\title{
Distribuição de densidade e estrutura populacional de Pilumnus dasypodus Kingsley (Crustacea, Decapoda, Xanthidae) na llha do Farol, Matinhos, Paraná, Brasil ${ }^{1}$
}

\author{
Cláudia Regina Bosa ${ }^{2}$ \\ Setuko Masunari ${ }^{3}$
}

\begin{abstract}
Density distribution and population structure of Pilumnus dasypodus Kingsley (Crustacea, Decapoda, Xanthidae) from Farol Isle, Matinhos, Paraná, Brazil. A study of the population of the xanthid crab Pilummus dasypodus Kingsley, 1879 from rocky shore at the Farol Isle (25 $51^{\prime}$ 'S and $48^{\circ} 32^{\prime} \mathrm{W}$ ) was carried out in the following aspects: temporal and spatial distributions of density, annual fluctuation of the sex ratio, size composition of the population and reproductive activities of the species. Monthly, four levels in relation to emmersion time within intertidal zone were sampled, from May/90 to April/91, but Piluminus dasypodus was obtained only in the levels 2,3 and 4 . The surface water temperature ranged from $16.0^{\circ} \mathrm{C}$ (July/90) to $28.0^{\circ} \mathrm{C}$ (February/91). A total of 775 individuals of Pilumnus dasypodus were collected among which, 92 were ovigerous females. The population density ranged from 14.63 ind. $\mathrm{m}^{-3}$ (February/91) to 148.00 ind. $\mathrm{m}^{-3}$ (March/91). Higher densities were observed in the level 4 , a local of permanent submersion. The sex ratio was $1: 1$ in almost all months. The carapace width varied from 1.01 to $8.28 \mathrm{~mm}$ for males, from 1.01 to $7.18 \mathrm{~mm}$ for females and 0.01 to $1.00 \mathrm{~mm}$ for juveniles. The fecundity ranged from 81 to 1834 eggs per female. The species has continuous reproduction with two peaks of recruiting in the year. There was a positive relationship, with weak correlation rate, between the carapace width of the ovigerous females and the number of eggs in the abdomen. The rocky shore at Farol Isle is a complex environment which harbor the decapod Pilumnus dasypodus, for breeding and surviving.

KEY WORDS. Pilumnus dasypodus, population structure, Farol Isle, Paraná State
\end{abstract}

A distribuição espacial e a flutuação temporal da abundância dos organismos são dois dos aspectos ecológicos mais relevantes, e o conhecimento dos mesmos constitui um passo fundamental no entendimento dos processos de interrelação com o meio ambiente (BREWER 1994).

A zonação na faixa entremarés em costões rochosos do litoral marinho é universal, envolvendo na maioria das vezes o mesmo grupo de seres vivos em qualquer parte do mundo, dos trópicos aos polos (BARNES \& HUGHES 1988). A zonação é mais evidente dentre os organismos sésseis, porém, aqueles vágeis como os decápodos também têm uma distribuição zonada, devido ao tempo diferenciado de emersão, o qual constitui um estresse térmico, de dessecação e de acesso reduzido ao oxigênio dissolvido e ao alimento (LEVINTON 1982).

1) Contribuição número 1172 do Departamento de Zoologia, Universidade Federal do Paraná.

2) Curso de Pós-graduação em Zoologia, Departamento de Zoologia, Universidade Federal do Paraná. Bolsista da CAPES.

3) Departamento de Zoologia, Universidade Federal do Paraná. Caixa Postal 19020, 81531-990 Curitiba, Paraná, Brasil. E-mail: setmas@bio.ufpr.br 
No Brasil, os trabalhos que versam sobre a distribuição zonada dos decápodos restringem-se aos de CALADO \& LACERDA (1993) que trabalharam nas praias do Estado de Pernambuco e de MASUNARI \& DUBIASKI-SILVA (1998) que trataram destes animais no Estado do Paraná. A composição de decápodos do sublitoral não consolidado foi estudada por FRANSOZO et al. (1992), no litoral norte do Estado de São Paulo.

No litoral de Pernambuco, o supralitoral de praias abrigadas é caracterizado pela presença de Armases angustipes (Dana, 1852) (Grapsidae), o mediolitoral por espécies de Xanthidae, Alpheidae, Porcellanidae, Diogenidae, Ocypodidae e por Pachygrapsus transversus (Gibbes, 1850) e Armases angustipes (ambos Grapsidae) e, finalmente, o infralitoral por espécies de Majidae e Palaemonidae (CALADO \& LACERDA 1993).

No Estado do Paraná, MASUNARI \& DUBIASKI-SILVA (1998) descreveram a distribuição zonada dos Crustacea Decapoda da Ilha do Farol, em Matinhos. O supralitoral é caracterizado pelas espécies resistentes à dessecação como Armases angustipes e Metasarma rubripes (Rathbun, 1897). No mediolitoral, estratégias adaptativas variadas foram observadas em quatro representantes da família Xanthidae, do Porcellanidae Petrolisthes armatus (Gibbes, 1850) e do Grapsidae Pachygrapsus transversus. No infralitoral houve maior diversidade de espécies de Decapoda, com predominância daquelas de pequeno porte, incluindo Pilumnus dasypodus Kingsley, 1879.

A distribuição temporal do Decapoda Porcellanidae Petrolisthes armatus da faixa entremarés da Ilha do Farol, Estado do Paraná, foi tratada por OLIVEIRA \& MASUNARI (1995), os quais concluíram que a espécie se reproduz continuamente durante $o$ ano com duas coortes principais (a de verão e a de inverno).

Posteriormente, MASUNARI et al. (1998) descreveram a flutuação temporal de densidade das espécies de Decapoda da Ilha do Farol, as quais possuem período reprodutivo distinto, na maioria, nos meses mais quentes. Porém, os valores de densidade da maioria das espécies não mostraram qualquer correlação com a flutuação de temperatura ou da salinidade.

O presente trabalho constitui um estudo descritivo das distribuições espacial (zonada) e temporal de densidade e aspectos da estrutura das populações de Pilumnus dasypodus na praia rochosa da Ilha do Farol, no litoral do Estado do Paraná. Esta espécie é um dos Xanthidae mais numerosos da praia rochosa da Ilha do Farol (MASUNARI et al. 1998). No Brasil, esta família está representada por 48 espécies e a distribuição geográfica da espécie abrange da Paraíba até Santa Catarina. Ela é encontrada em fundos de areia, conchas, corais, em raízes de árvores de manguezais e pilares de embarcadouros (MELo 1996).

\section{MATERIAL E MÉTODOS}

O mapa e a descrição da área de estudo, bem como a metodologia de coleta encontram-se em MASUNARI et al. (1998). As coletas foram realizadas de maio/90 a abril/91. A altura mínima prevista da maré de sizígia para a Barra do Porto de Paranaguá - Canal da Galheta, Paraná, nos dias de coleta foi de $0,0 \mathrm{~m}$ em todos os 
meses, com exceção de dezembro $(0,1 \mathrm{~m})$ e de novembro $(0,2 \mathrm{~m})$. A amplitude de oscilação da temperatura do ar foi de $13^{\circ} \mathrm{C}$ (maio) a $27^{\circ} \mathrm{C}$ (março), enquanto a temperatura da água de superfície foi de $16^{\circ} \mathrm{C}$ (julho) a $28^{\circ} \mathrm{C}$ (fevereiro) (MASUNARI et al. 1998). Não houve coleta em novembro/91 devido à tempestade que ocorreu no dia de amostragem. Quatro pontos de coleta denominados de Nível 1, 2, 3 e 4 foram estabelecidos ao longo de uma transecção perpendicular à linha costeira, conforme o tempo de emersão na região entremarés: 8-12 horas, 4-8 horas, 0-4 horas e sempre submerso, respectivamente. Após coleta manual e triagem das amostras, os exemplares de Pilumnus dasypodus foram identificados, contados e o sexo e o estágio de desenvolvimento reconhecidos. Fêmeas ovígeras foram anotadas. A máxima largura da carapaça $(\mathrm{mm})$ dos caranguejos foi tomada com o auxílio de um microscópio estereoscópico equipado com ocular graduada. A densidade animal foi calculada em número médio de indivíduos por $\mathrm{m}^{3}$ de volume amostrado. Para detectar uma possível ocorrência de diferenças significativas na freqüência de machos e fêmeas, foi utilizado o teste do $X^{2}$ (quiquadrado), com um nível de significância de 5\%. Para a composição de tamanho, os indivíduos foram agrupados em classes de largura da carapaça, com os seguintes limites (em mm): $0,01 \leftrightarrow 1,00$; $1,01 \leftrightarrow 2,00 ; 2,01 \leftrightarrow 3,00 ; 3,01 \leftrightarrow 4,00 ; 4,01 \leftrightarrow 5,00 ; 5,01 \leftrightarrow 6,00 ; 6,01 \leftrightarrow 7,00 ;$ $7,01 \leftrightarrow 8,00$ e $8,01 \leftrightarrow 9,00$. Neste estudo, foi computado o total de indivíduos ocorrentes nos quatro níveis. As fêmeas ovígeras tiveram os ovos retirados, contados e o diâmetro medido, os quais foram classificados em três estágios de maturação para o estudo de fecundidade de espécie.

\section{RESULTADOS}

Pilumnus dasypodus faltou apenas no Nível 1 dos quatro estudados, somando, respectivamente 11, 52 e 712 indivíduos nos Níveis 2, 3 e 4. Entretanto, somente no Nível 4 a espécie esteve presente em todos os meses, onde também, foram registradas as maiores densidades, as quais variaram de 8,52 ind. $\mathrm{m}^{-3}$ (maio) a 257,45 ind. $\mathrm{m}^{-3}$ (dezembro). A curva de flutuação de densidade da espécie é definida pelos valores de densidade registrados neste nível e tem dois picos: o primeiro ocorreu em dezembro e o segundo, menos acentuado, em março (Fig. 1). No Nível 3 , a espécie não ocorreu em setembro, fevereiro e março e as densidades variaram de 2,27 ind. $\mathrm{m}^{-3}$ (Julho) a 21,79 ind. $\mathrm{m}^{-3}$ (dezembro). Já no Nível 2, ela ocorreu apenas em julho e agosto, com valores de 24,32 ind. $\mathrm{m}^{-3}$ e 6,90 ind. $\mathrm{m}^{-3}$, respectivamente (Fig. 1).

De um modo geral, a densidade populacional flutuou no ano, num padrão de valores altos nos meses mais quentes e baixos nos frios. Com exceção de janeiro e fevereiro, as densidades acima de 100,00 ind. $\mathrm{m}^{-3}$, no Nível 4, estiveram associadas às temperaturas iguais ou superiores a $20^{\circ} \mathrm{C}$ (Fig. 1).

Os machos foram mais abundantes que as fêmeas em todos os meses, exceto em outubro, quando a freqüência relativa de fêmeas foi significativamente maior que a dos machos. O teste de $X^{2}$ (qui-quadrado) mostrou diferenças significativas em junho, dezembro, janeiro e abril. Nos demais meses, foi observada a proporção esperada de 1:1 (Fig. 2). 


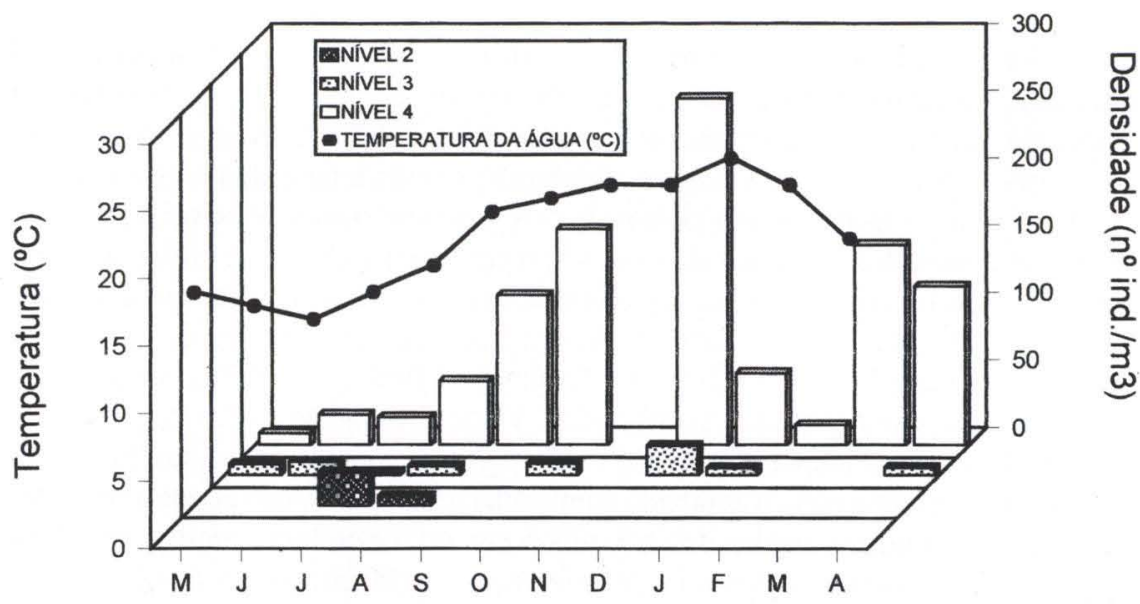

Fig. 1. Pilumnus dasypodus. Flutuação anual da densidade $\left(n^{0}\right.$ ind. $\left.\mathrm{m}^{-3}\right)$ registrada nos Niveis 2, 3 e 4 durante o período de estudo. Não houve representantes no Nível 1. A flutuação anual da temperatura da superfície da água, também, está apresentada.

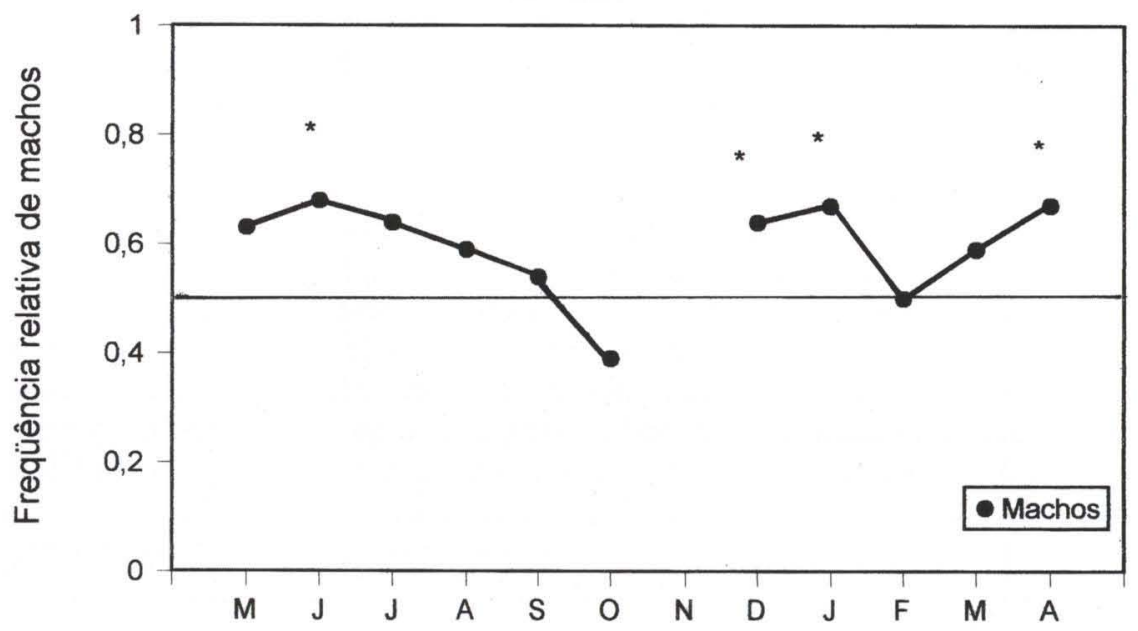

Fig. 2. Pilumnus dasypodus. Proporção mensal de sexos da população ao longo do periodo de estudo. Valores acima de 0,5 indicam predominância de machos $\left({ }^{*}=\right.$ diferença significativa).

A figura 3 mostra a distribuição de Pilumnus dasypodus nas classes de largura da carapaça, durante os meses de coleta. Ocorreram machos e fêmeas em todos os meses amostrados. Os machos apresentaram maior amplitude de variação da largura da carapaça do que as fêmeas. Juvenis foram registrados apenas em dezembro e em abril. Em maio, observa-se uma amplitude de variação da largura da carapaça de $1,01 \mathrm{~mm}$ a $3,01 \mathrm{~mm}$, com maior freqüência de indivíduos na classe 

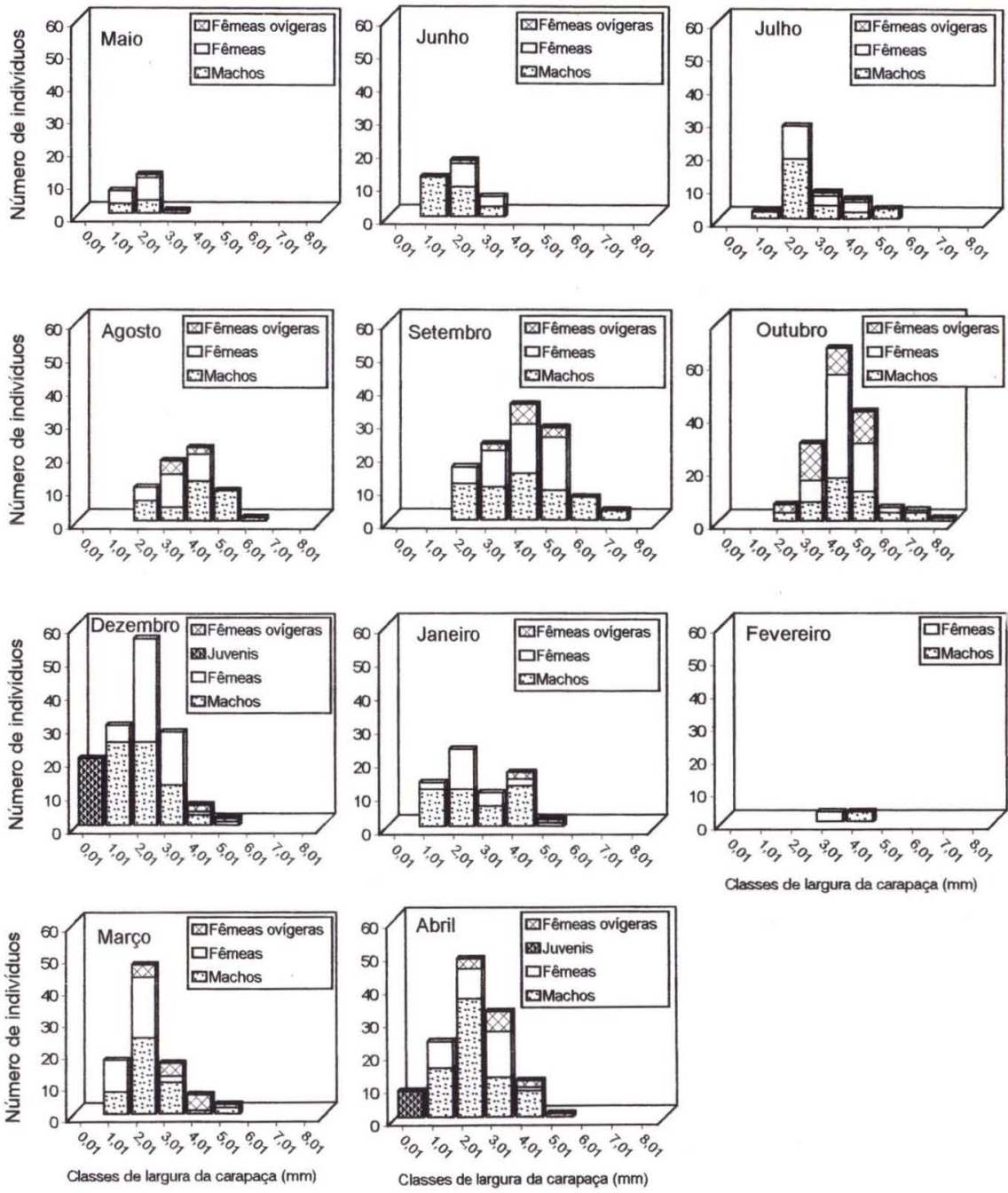

Fig. 3. Pilumnus dasypodus. Distribuição dos indivíduos nas diversas classes de largura da carapaça $(\mathrm{mm})$, durante os meses de estudo. Não houve coleta em novembro.

2,01-3,00 mm. Em junho e julho, a maior freqüência de indivíduos continua na classe 2,01-3,00 mm, porém, em julho, a população tem maior amplitude de variação da largura da carapaça, ocorrendo indivíduos de 1,01 (em freqüência bem menor) a 5,01 mm. Em agosto, há um deslocamento da classe modal para 4,01-5,00 mm, surgindo mais uma classe $(6,01-7,00 \mathrm{~mm})$ porém, desaparecendo a de 1,01-2,00 $\mathrm{mm}$. Em setembro, a classe com maior freqüência de indivíduos continua sendo a de 4,01-5,00 mm, e surge a classe 7,01-8,00 $\mathrm{mm}$; isto sugere que, os animais ao longo destes meses aumentaram o seu tamanho. Em outubro, a classe modal continua a mesma, mas surge uma nova classe $(8,01-9,00 \mathrm{~mm})$, e a de 2,01-3,00 
$\mathrm{mm}$ apresenta-se bastante reduzida; isto confirma que os animais da população ainda estão crescendo. Em dezembro, aparece a classe 0,01-1,00 mm, o que indica uma entrada de juvenis na população (recrutamento); a classe de maior freqüência de indivíduos volta a ser a de 2,01-3,00 mm bem como em janeiro. Em fevereiro, observam-se indivíduos somente nas classes 3,01-4,00 $\mathrm{mm}$ e 4,01-5,00 $\mathrm{mm}$ em número igual. Em março, a classe modal é a de 2,01-3,00 mm, quando há indivíduos até na classe 5,01-6,00 mm. Em abril, houve a segunda entrada de juvenis no ano (classe $0,01-1,00 \mathrm{~mm}$ ), e as classes de maior largura da carapaça tiveram a freqüência de indivíduos diminuída. Portanto, a população de Pilumnus dasypodus apresenta crescimento de maio a outubro, com uma entrada principal de juvenis em dezembro-janeiro, um segundo período de crescimento de dezembro a março, e um segundo recrutamento, menos pronunciado, em março-abril.

A figura 4 mostra a distribuição das classes de largura da carapaça de Pilumnus dasypodus nos três níveis de ocorrência durante o período de estudo. No Nível 2, foram coletados 11 indivíduos (somente machos), com largura de carapaça de $1,01 \mathrm{~mm}$ a $5,00 \mathrm{~mm}$. No Nível 3, ocorreram machos $(\mathrm{n}=36)$ e fêmeas $(\mathrm{n}=16)$. Os machos apresentaram uma amplitude de variação da largura da carapaça de 1,01 $\mathrm{mm}$ a $6,00 \mathrm{~mm}$, enquanto que as fêmeas, de 2,01 a 5,00 $\mathrm{mm}$. No Nível 4, ocorreram 712 indivíduos dos quais 383 machos (1,01-9,00 mm) 301 fêmeas $(1,01-8,00 \mathrm{~mm})$ e 28 juvenis $(0,01-1,00 \mathrm{~mm})$; em todos os níveis, os machos foram predominantes e maiores que as fêmeas.

Houve fêmeas ovígeras em todos os meses de coleta, exceto em fevereiro (Fig. 5), o que indica uma reprodução contínua da espécie ao longo do ano. De uma forma geral, a curva de distribuição de freqüência absoluta das fêmeas não ovígeras lembra a da população total. Entretanto, a das fêmeas ovígeras foi diferente especialmente a partir de dezembro até abril. Porcentagens destas acima de $30 \%$ ocorreram em outubro $(36,49 \%)$ e maio $(31,11 \%)$, o que indica maior atividade reprodutiva das fêmeas nestes meses.

Foram reconhecidas três fases de desenvolvimento de ovos conforme a coloração e o diâmetro destes no material fixado. Na primeira fase, os ovos tiveram coloração amarelo-pálido e diâmetro médio de $0,31 \mathrm{~mm}$. Na segunda, foram alaranjados com diâmetro médio de $0,37 \mathrm{~mm}$. Na terceira, os ovos tiveram cor marrom-clara com duas pequenas pontuações negras; correspondentes aos olhos do embrião prestes a eclodir. Estes ovos embrionados apresentaram um diâmetro médio de $0,43 \mathrm{~mm}$. A relação entre a cor dos ovos e o respectivo diâmetro indica que, ao longo da embriogênese, os ovos tendem a escurecer na cor e a aumentar em diâmetro.

Estas fases foram encontradas em qualquer das classes de largura da carapaça das fêmeas ovígeras: fêmeas pequenas portaram massas de ovos escuros e as grandes, massas de ovos claros e vice-versa. Este fato indica uma multiparidade da espécie e comprova a reprodução contínua das fêmeas durante o ano.

A figura 6 mostra a relação entre a largura da carapaça das fêmeas ovígeras e o respectivo número de ovos. Houve uma tendência linear na correlação (equação da reta: $\mathrm{y}=3,5272-11,0390 \mathrm{x})$, porém, o coeficiente foi baixo $(\mathrm{r}=0,5698)$ 
mostrando fraca aderência dos pontos em relação à reta. Fêmeas menores mostraram menor amplitude de variação do número de ovos na massa ovígera, enquanto as maiores, maior amplitude (Fig. 7).

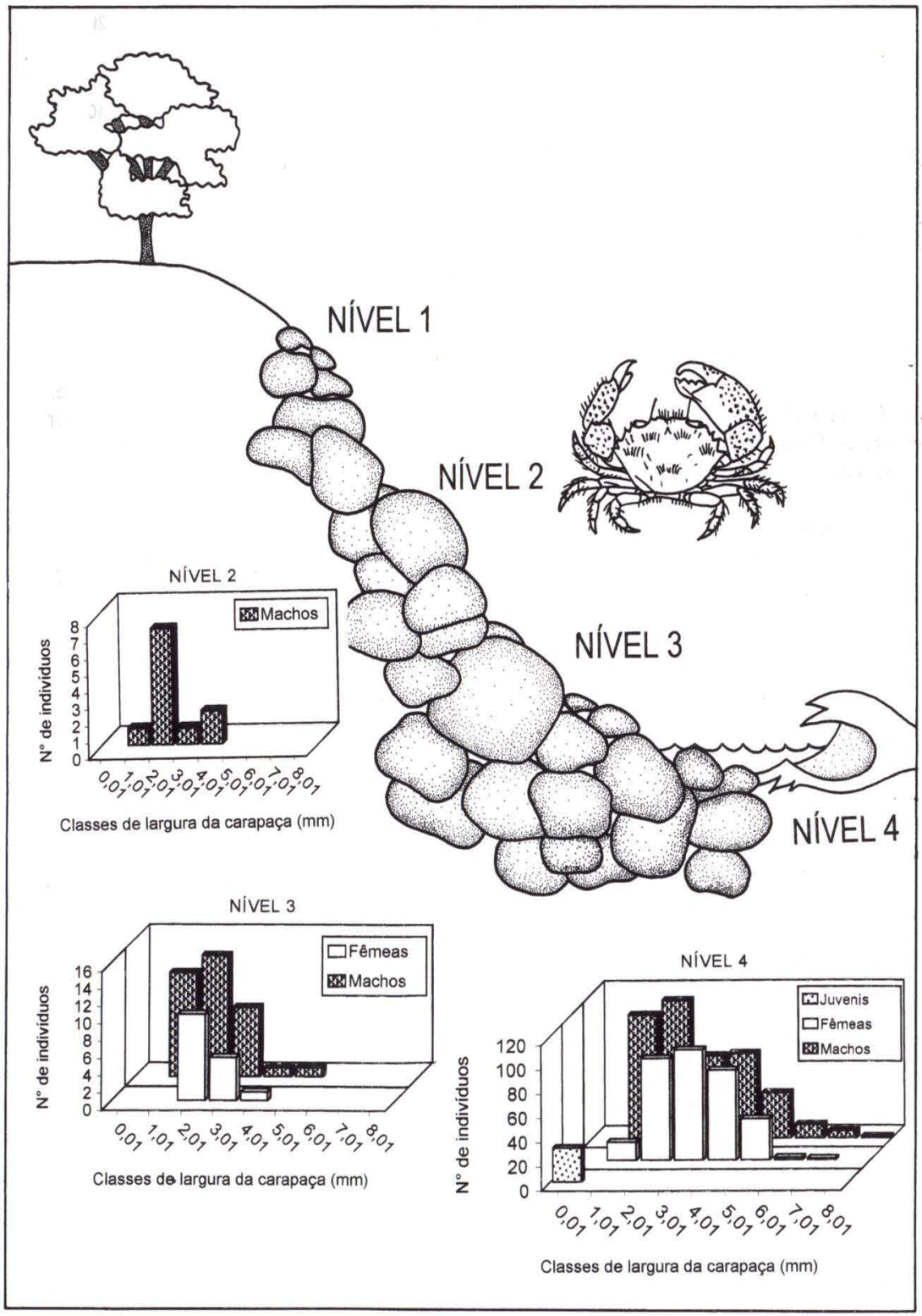

Fig. 4. Pilumnus dasypodus. Distribuição espacial e nas classes de largura da carapaça $(\mathrm{mm})$ dos individuos coletados nos Niveis 2,3 e 4, durante o periodo de estudo. 


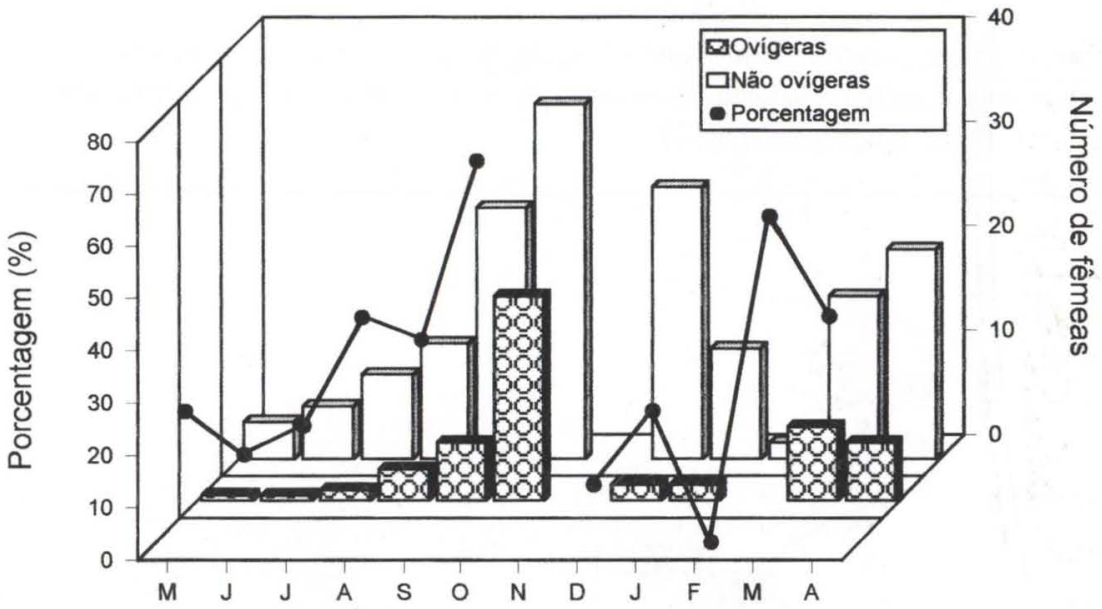

Fig. 5. Pilumnus dasypodus. Distribuição de freqüência absoluta de fêmeas não ovigeras e ovígeras e frequeência relativa (\%) de fêmeas ovígeras nos meses de coleta durante o periodo de estudo

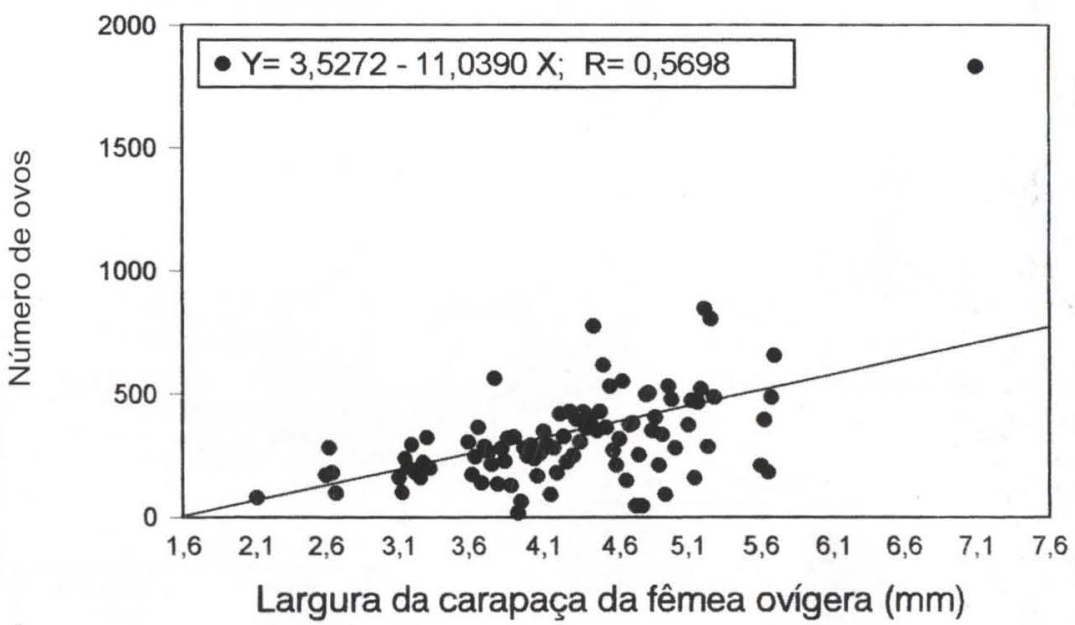

Fig. 6. Pilumnus dasypodus. Correlação entre o número de ovos presentes na massa ovigera e a largura da carapaça da fêmea ovígera $(\mathrm{mm})$.

\section{DISCUSSÃO}

Altas densidades relacionadas com temperaturas elevadas, como as observadas nas populações de Pilumnus dasypodus do presente trabalho, constituem padrão somente para Petrolisthes armatus dentre os Decapoda ocorrentes na Ilha do Farol. A maioria deles parece não ser influenciada diretamente pela temperatura da água de superfície (MASUNARI et al. 1998). A densidade baixa registrada em 


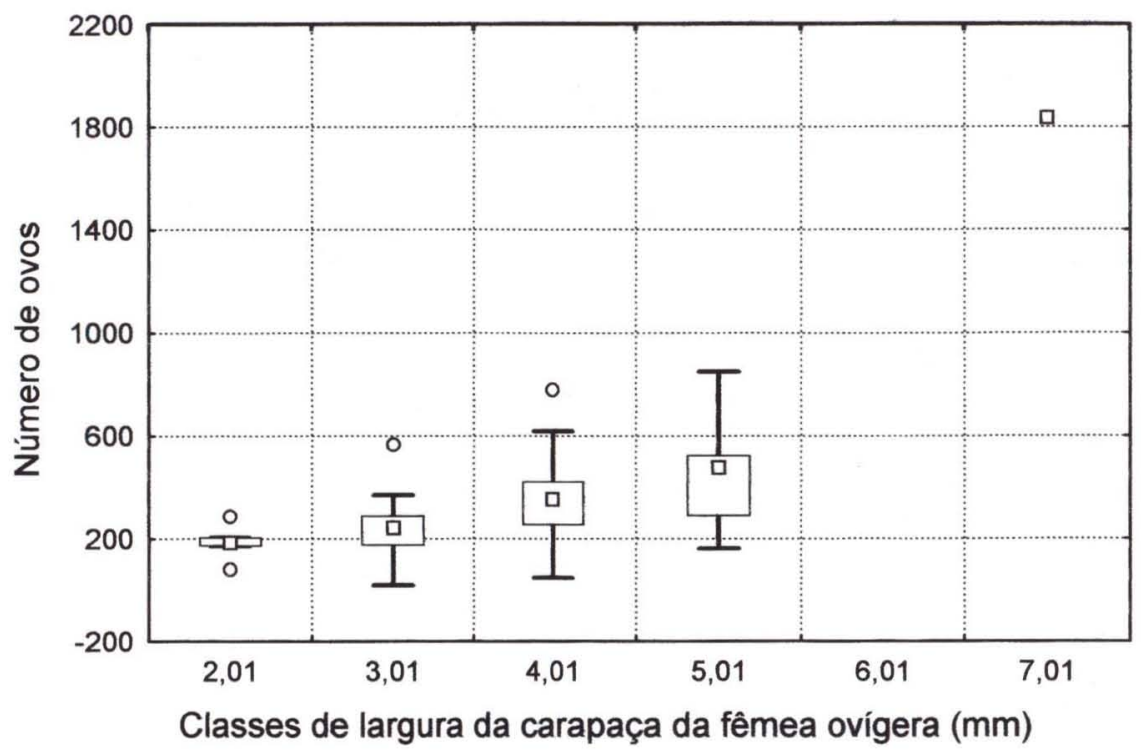

Fig. 7. Pilumnus dasypodus. Média, desvio padrão e amplitude de variação do número de ovos presentes na massa ovígera das fêmeas ovígeras de diversas classes de largura da carapaça $(\mathrm{mm})$. Na classe 7,01-8,00 mm houve apenas uma fêmea com 1834 ovos.

fevereiro, apesar da alta temperatura da água de superfície neste mês, deve ter sido devido à amostragem prejudicada pelo represamento das águas e conseqüente abaixamento incompleto do nível d'água na maré de sizígia.

A entrada de juvenis na população de Pilumnus dasypodus é semelhante à de Petrolisthes armatus, segundo OlIVEIRA \& MASUNARI (1995), nos quais ocorrem dois períodos principais de recrutamento ao longo de um ano. No presente estudo, os recrutamentos ocorreram em dezembro e em abril, enquanto que em Petrolisthes armatus ocorreram em dois períodos dezembro-abril e junho-julho.

O tamanho máximo de $8,28 \mathrm{~mm}$ de largura da carapaça observado em Pilumnus dasypodus (um macho) no presente estudo, mostra que a população da Ilha do Farol compõe-se de indivíduos bem menores que os citados na literatura, onde há registros de largura da carapaça de $15,0 \mathrm{~mm}$ para macho e $10,3 \mathrm{~mm}$ para fêmea (WILliams 1984). Como a espécie pode ocorrer em profundidades de até 52 $\mathrm{m}$, conforme o mesmo autor, é possível que em profundidades maiores que as estudadas no presente trabalho, as populações tenham maior largura de carapaça.

A presença constante apenas no Nível 4 e em densidades mais altas das populações de Pilumnus dasypodus em todos os meses de coleta, indica que esta espécie tem pouca resistência à dessecação. Como este Decapoda é um dos menores em porte, a hipótese de MASUNARI \& DUBIASKI-SILVA (1998) continua válida também para a presente espécie: aquelas de porte menor são mais sensíveis à dessecação. Corrobora esta assunção a ocorrência desta espécie no Nível 2 apenas em julho e agosto, quando as temperaturas do ar normalmente são mais amenas 
nestes meses e, portanto, a força de dessecação é menor. Além disso, juvenis nunca foram registrados nos níveis superiores, comprovando a suscetibilidade de indivíduos pequenos à exposição ao ar. No Nível 3, observa-se uma situação intermediária: presença em quase todos os meses, porém, em baixas densidades.

A proporção de sexos mendeliana (1:1) observada em sete meses dos onze observados mostra a diversidade deste fator dentre os Crustacea (SASTRY 1983).

A população de Pilumnus dasypodus do presente trabalho, se enquadra nos padrões do modelo anômalo segundo WENNER (1972). De um modo geral, os machos são maiores que fêmeas, provavelmente, devido ao fato das fêmeas canalizarem energia para a produção de elementos reprodutivos, enquanto que os machos podem ter um crescimento adicional. Machos com maior tamanho que fềmeas também são observados em outros Decapoda como Callinectes danae Smith, 1869 (BRANCO \& MASUNARI 1992) e Petrolisthes armatus (OLIVEIRA \& MASUNARI 1995).

Com relação à proporção de sexos ao longo dos níveis de amostragem, observa-se que no Nível 2 ocorrem apenas machos; no Nível 3 a freqüência de machos ainda é maior que a de fêmeas e, somente no Nível 4, a freqüência de machos e fêmeas fica equiparada. Pode-se sugerir que machos de Pilumnus dasypodus apresentam menor dependência da água pois, machos tão pequenos quanto $1,0 \mathrm{~mm}$ de largura da carapaça foram registrados no Nível 2 (ver figura 4). Dentre as fêmeas, aquelas encontradas no Nível 3 mediram mais de $2 \mathrm{~mm}$ de largura da carapaça (ver figura 4). A forte dominância de fêmeas nos níveis inferiores pode estar relacionada com a atividade reprodutiva das mesmas. Ao tornarem-se ovígeras, as fêmeas em condições de submersão constituem uma segurança para as larvas zoea recém eclodidas, as quais deverão compor o plâncton para completar o seu desenvolvimento. A sobrevivência destas larvas estaria ameaçada se a eclosão ocorresse em níveis sujeitos à emersão, mesmo que seja temporária, como é o caso dos Níveis 2 e 3. Corrobora esta hipótese, a ocorrência da maioria das fêmeas ovígeras no Nível 4, contra apenas duas no Nível 3 e ausência no Nível 2.

A reprodução contínua registrada em Pilumnus dasypodus parece ser uma regra dentre os Decapoda de clima subtropical quente como é o caso da região de Matinhos, Paraná. Ela é observada em outras espécies como Petrolisthes armatus, Menippe nodifrons Stimpson, 1860, Synalpheus fritzmuelleri Coutière, 1909 e Alpheus bouvieri A. Milne Edwards, 1878 da Ilha do Farol (OlIVEIRA \& MASUNARI 1995; MASUNARI et al. 1998). A porcentagem de fêmeas ovígeras de Pilumnus dasypodus quando comparada com a de Petrolisthes armatus (OLIVEIRA \& MASUNARI 1995) pode ser considerada baixa, pois nesta última, o número de fêmeas ovígeras ao longo dos meses de estudo variou de 3 a $89 \%$, enquanto que, naquela variou de 0 a $36,49 \%$.

O baixo índice de correlação entre o número de ovos presentes na massa ovígera e o tamanho das fêmeas ovígeras de Pilumnus dasypodus na Ilha do Farol, indica que este parâmetro tem influência de outras variáveis além da largura da carapaça. Uma primeira hipótese reside na possibilidade da perda de ovos da massa ovígera, à medida que os mesmos vão amadurecendo (passando da cor clara para a mais escura), certamente, para acomodar os ovos cujo diâmetro está aumentando 
num espaço limitado do abdome da fêmea. Assim, o número de ovos presente na massa ovígera seria uma função, também, do estágio de desenvolvimento em que os mesmos se encontram.

A crescente amplitude de variação do número de ovos presentes na massa ovígera com o aumento da largura da carapaça das fêmeas ovígeras (ver figura 7), pode estar relacionada com a multiparidade da espécie. Assim, dentre as fêmeas de porte maior, a variabilidade no número de ovos é maior porque elas devem estar em atividade reprodutiva de diversas ordens. Corrobora esta assunção, a inexistência de correlação entre o diâmetro dos ovos e o tamanho das fêmeas ovígeras. Certamente, fềmeas grandes ou pequenas com muitos e pequenos ovos são aquelas que desovaram recentemente e os mesmos estariam no estágio inicial da embriogênese. Por outro lado, fêmeas grandes ou pequenas com menos número e grandes ovos, corresponderiam àquelas portadoras de ovos em adiantado estágio de desenvolvimento. A presença de uma única fêmea ovígera pertencente à classe 7,01-8,00 mm, portando 1834 ovos na massa ovígera, indica que a espécie pode ter representantes muito maiores que os obtidos no presente estudo e, também, possuir maior número de ovos.

O presente estudo mostra, mais uma vez, a importância da preservação dos costões rochosos da Ilha do Farol, os quais abrigam várias espécies de Decapoda que neles realizam integralmente a fase bentônica do seu ciclo de vida.

\begin{abstract}
AGRADECIMENTOS. Ao Prof. Joel Maurício Corrêa da Rosa e à acadêmica Márcia Kotelok do Departamento de Estatística da Universidade Federal do Paraná, pelas análises estatísticas do presente estudo. Aos biólogos Dra Janete Dubiaski da Silva, Dra Edinalva Oliveira, Dr. Joaquim Olinto Branco, Dra. Vânia Graciele Lezan Kowalczuk e André Henrique Gaida Sicuro pela coleta do material biológico do presente estudo. À Pryscilla Fanini Wowk, bolsista de Iniciação Científica, pela arte final da figura 4 do presente trabalho.
\end{abstract}

\title{
REFERÊNCIAS BIBLIOGRÁFICAS
}

BARNES, R.S.K \& R.N. HughES. 1988. An introduction to marine ecology. London, Blackwell, 351p. Branco, J.O. \& S. Masunari. 1992. Estrutura populacional de Callinectes danae Smith, 1869 (Decapoda, Portunidae) da Lagoa da Conceição, SC. Acta Biol. Paranense, Curitiba, 21 (1-4): 37-56.

BREWER, R. 1994. The science of ecology. Philadelphia, Saunders, VIII+773p.

CALADO, T.C. \& P.R. LACERDA. 1993. Zonação vertical e variação sazonal da carcinofauna (Decapoda e Isopoda) do costão rochoso de Calhetas (Cabo-Pernambuco-Brasil). Arq. Biol. Tecnol., Curitiba, 36 (4): 731-738.

Fransozo A.; M. Negreiros-Fransozo; F.L.M. Mantelatto; M. Pinheiro \& S. Santos. 1992. Composição dos Brachyura (Crustacea, Decapoda) do sublitoral não consolidado na Enseada da Fortaleza, Ubatuba (SP). Rev. Brasil. Biol. 52 (4): 667-675.

Levinton, J.S. 1982. Marine ecology. New Jersey, Prentice-Hall, XV+526p.

Masunari, S. \& J. Dubiaski-Silva. 1998. Crustacea Decapoda da praia rochosa da Ilha do Farol, Matinhos, Paraná. II. Distribuição espacial de densidade das populações. Revta bras. Zool. 15 (3): 643-664.

MASUnARI, S.; E. Oliveira \& V.G.L. KowalCZuK. 1998. Crustacea Decapoda da praia rochosa da Ilha do Farol, Matinhos, Paraná. I. Distribuição temporal de densidade das populações. Revta bras. Zool. 15 (1): 219-239. 
Melo, G.A.S. 1996. Manual de identificação dos Brachyura (caranguejos e siris) do litoral brasileiro. São Paulo, FAPESP-Plêiade, 603p.

Oliveira, E. \& S. MASUnARI. 1995. Estrutura populacional de Petrolisthes armatus (Gibbes, 1850) (Decapoda, Anomura, Porcellanidae) da Ilha do Farol, Caiobá, Paraná. Revta bras. Zool. 12 (2): 355-371.

SASTRY, A.N. 1983. Ecological aspects of reproduction, p. 179-270. In: F.J. VERnBERG \& W.B. VERnBERG (Eds). Environmental adaptations. The biology of Crustacea. New York, Academic, Vol. 8, XXVI+383p.

WENNER, A.M. 1972. Sex ratio as a function of size in marine Crustacea. Amer. Natur. 106 (949): 321-350.

Williams, A.B. 1984. Shrimps, lobsters, and crabs of the Atlantic coast of the Eastern United States, Maine to Florida. Washington, Smithsonian Institution Press, XVIII+550p.

Recebido em 30.IX.1999; aceito em 21.XII.2000. 